\title{
Análisis de Discurso. Principios y procedimientos
}

\author{
Eni Orlandi \\ Traducción de Elba Soto
}

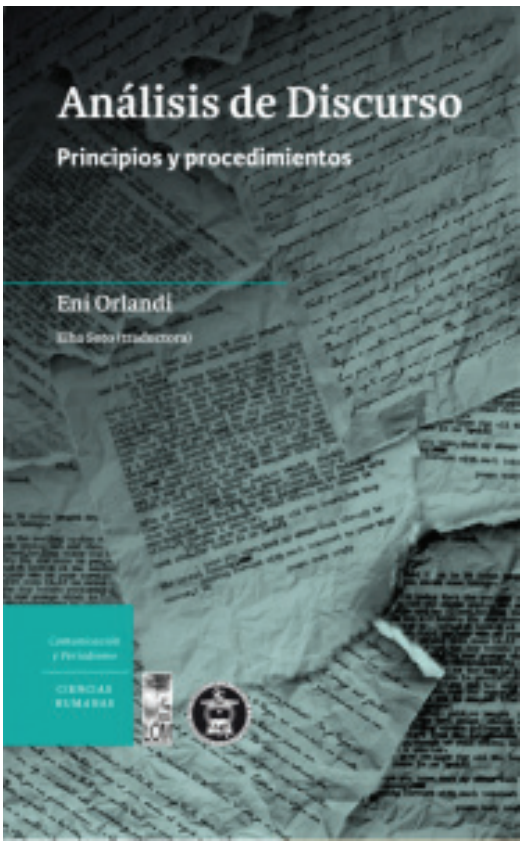

\section{Rebecca López-Morales ${ }^{*}$}

Análisis de Discurso. Principios y procedimientos, constituye la primera publicación en Chile de la destacada profesora e investigadora brasileña Eni Orlandi, en la que se exponen los planteamientos básicos de la

** Profesora de Lenguaje y Comunicación. Estudiante de Magíster en Comunicación, Universidad Austral de Chile. Correo electrónico: pichimalen.Im@gmail.com 
corriente discursiva francesa; y que se comprende como un texto introductorio al Análisis de Discurso (AD). Además, significa un aporte tanto para el ámbito académico como cultural, ya sea en la formación de analistas de discurso o para la lectura de quienes se interesan por conocer nuestra relación con el lenguaje y con el mundo.

El libro se compone básicamente por tres capítulos centrales: 1) El Discurso; 2) Sujeto, Historia, Lenguaje; y 3) Dispositivo de análisis; y de sus Conclusiones. Su lectura nos permite entender el AD haciendo un recorrido por sus conceptos, pasando por la metodología y llegando a los procedimientos analíticos, para luego entregar una síntesis que vincula el discurso con la ideología como "mecanismo estructurante del proceso de significación" (2012: 100). De este modo, la revisión completa del libro entrega a su lector una forma de entender el lenguaje que abre una perspectiva de trabajo basada en el discurso como proceso sociohistórico. Así, Orlandi ofrece un conocimiento base que nos permite tomar la posición de analistas frente a los discursos, entendiendo que el lenguaje significa no sólo de forma simbólica, sino también de forma política.

El primer capítulo introduce una nueva mirada respecto del discurso, entendiéndolo como proceso, al mismo tiempo que nos da las claves para comprender el Análisis de Discurso como un trabajo social que se constituye desde el hombre y desde su/la historia. De este modo, la autora sitúa el AD entre las Ciencias del Lenguaje y las Ciencias Sociales, buscando la transformación de ambas disciplinas en pos de comprender cómo el lenguaje produce sentidos desde/hacia los sujetos. En esta línea, Orlandi explica cómo en el AD confluyen tres dominios disciplinares principales: Lingüística, Marxismo y Psicoanálisis; y cómo estos campos de conocimiento son cuestionados y resignificados en la construcción del discurso como objeto de estudio. Así, se plantea pensar en el discurso de manera distinta al mensaje, en virtud de que este último se limita a la entrega de información; en cambio, en el discurso suceden diversos procesos que vinculan los sentidos del lenguaje con los sujetos y en esa relación se manifiestan múltiples efectos sometidos a la ideología.

El segundo capítulo presenta una serie de características que definen el funcionamiento del lenguaje considerando la relación entre el sujeto y la historia. En primer lugar, se revisa la propuesta intelectual en la que se sitúa el Análisis de Discurso, dando cuenta de la relevancia de una nueva forma de comprender la noción de lectura, atravesada por una 
posición crítica que cuestiona la hermenéutica. De este modo, la autora establece que el AD genera "nuevas prácticas de lectura". Es en esta nueva forma de interpretación que el analista guiará su investigación a ciertos resultados, en virtud de la formulación de las preguntas que desencadenarán su análisis. Para estos alcances resulta relevante el aporte de este texto en la incorporación de nuevos conceptos teóricos que sustentan el conocimiento en torno a los Estudios del Discurso en Chile. Dichos conceptos vienen a definir y a explicar las particularidades de esta área (inter)disciplinar, que permite al analista construir su análisis a partir de lo que su interés indica relevante, teniendo la facultad de decidir qué incluir y qué descartar en el camino de su investigación, lo que Orlandi llama "dispositivo analítico". De este modo, la autora plantea especificaciones que explican la importancia de la perspectiva que adopta el analista de discursos en determinadas investigaciones.

En este capítulo se identifican varias condiciones de producción de los discursos que nos permiten comprender cómo funciona el lenguaje desde los sujetos insertos en la sociedad. En esta línea, el sujeto se determina de acuerdo a su entorno; es decir, es efecto de su estructura social, y a partir de allí, en conjunto con la ideología, construye sus discursos. Otro de los aportes significativos de este apartado se da lugar en la revisión de la formación discursiva. Esta está relacionada directamente con lo que Orlandi identifica como "interdiscurso" y que básicamente se refiere a la memoria discursiva que comporta un discurso y que adquiere sentidos que han sido olvidados por el productor discursivo, lo que genera que en el momento de la producción tengamos "la ilusión de ser el origen de lo que decimos cuando, en realidad, retomamos sentidos pre-existentes" (2012: 42). Es interesante comprender el discurso desde estas condiciones o características, puesto que nos entregan un enfoque íntegro para comprender cómo significan los textos y cómo los sentidos y los sujetos se mueven y (se) significan.

El tercer capítulo constituye los procedimientos analíticos para comprender el modo en que los discursos generan sentidos. Además de presentarnos las bases del análisis y de la metodología paso a paso, Orlandi describe aquello que el analista de discurso debe comprender de acuerdo a esta forma de analizar y el por qué. En ese sentido, la autora establece diferencias principales para comprender el $A D$, entre las cuales enfrenta conceptos como texto/discurso, autor/sujeto, y sitúa a cada uno de ellos dentro o fuera del análisis en distintos momentos. Orlandi señala que el analista debe construir un dispositivo de interpretación 
que le permita comprender el texto a partir de todo aquello que puede observarse, así como de lo que no puede ser observado pero que, del mismo modo, constituye el sentido del discurso. En este procedimiento entran en juego todas aquellas características que la autora distingue en su segundo capítulo y que dan forma al funcionamiento del lenguaje. En esta línea, la ideología atraviesa cada una de ellas, estableciéndose materializada en lo dicho y en lo no dicho -siendo esto último tan significante como lo dicho. En otros términos, la ideología se presenta en los juegos simbólicos y transferencias que constituyen a los sujetos y a los sentidos. Resulta verdaderamente interesante la forma en que la autora va conectando todos sus planteamientos, permitiendo a los lectores seguir sus ideas de una manera didáctica. Así, vamos comprendiendo la importancia de una disciplina que debe valerse de otras ciencias que traspasan a la Lingüística y que vienen no solo a cuestionar, sino a complementar sus postulados.

En este capítulo, Orlandi retoma, además, una propuesta teórica (1989) que establece una tipología de discursos, basada específicamente en sus principios y que se vale de aquellos aportes teóricos más significativos de su libro. En este sentido, es interesante destacar cómo su propuesta funciona específicamente para el Análisis de Discurso, en tanto que la elección por clasificar un discurso en tal o cual tipo, dependerá de las tendencias que se presenten en el análisis.

De acuerdo con lo expuesto, se concluye que la traducción de esta obra al español conforma un gran aporte al entendimiento del Análisis de Discurso en Chile y Latinoamérica, por ofrecer una explicación integral y acabada, pasando por procesos analíticos que se aplican efectivamente, pero que hasta ahora no estaban teorizados. Eni Orlandi los explica y con ello nos entrega nuevas nociones para comprender el lenguaje como práctica socio-históricamente situada. Esta obra, sin duda, aporta a la reflexión en torno a la construcción de discursos, comprendiendo su base desde lo político y también desde lo simbólico. 